\title{
Identity in people with schizophrenia and in those after spinal cord injury
}

\begin{abstract}
Stressful events like severe illnesses and injuries impact self-experience. This study investigates the identity characteristics of people with schizophrenia and those following spinal cord injury. 30 participants from each group and members of the control group answered the Tennessee Self-Concept Scale and evaluated themselves on a semantic differential. The results indicate a confused identity in people with schizophrenia and important differences between the Real and the Ideal Self in patients following spinal cord injury (SCI). Responses of patients following SCI are less reliable, which may indicate the presence of defense mechanisms, and therefore less reliable. Our findings underscore the importance of self-experiencing focused education, psychotherapy and collaborations with relatives.
\end{abstract}

Keywords: schizophrenia, spinal cord injury, self-experience, confused identity
Volume 2 Issue 5 - 2015

Barbara Horvat

URI-SoA, Slovenia

Correspondence: Barbara Horvat, URI-SoA, Linhartova 5 I 1000, Ljubljana Slovenija, Slovenia , Tel 38641949506,

Email Barbara.horvat@ir-rs.si

Received: February 02, 2015 | Published: April 25, 2015
Abbreviations: SCI, spinal cord injury; CON, conflict; TOT, total self concept; MOR, moral; PHY, physical; PER, personal; FAM, family; SOC, social; ACA, academic/work; INC, inconsistent; SC, self-criticism; FG, faking good; RD, response distribution; IDN, identity; SAT, satisfaction; BHV, behavior; NMEC, national medical ethics committee of the republic of slovenia; $\mathrm{RD}$, response distribution

\section{Introduction}

Human beings have a lot of experiences with ourselves and a huge store of autobiographical memories, so we feel that we know ourselves. ${ }^{1}$ Each person is able to give self descriptions and provide answers to questions like: "Who am I?", "What is characteristic to me?" and "How do I fit in?". Answers of those questions represent the identity and the self-concept.

Those constructs are very connected. The self-concept represents the ideas about ourselves, while the identity is the description of who we are. Although the terms identity and self-concept seem to be in common, they are different. ${ }^{2}$ Self-concept exists only in one person's mind and summarizes aspects of different areas of someone's functioning and being. ${ }^{2}$ Fits $\&$ Warren ${ }^{3}$ distinguish: physical, personal, social, family, academic and moral aspects of self-concept. On the contrary identity is essentially social. ${ }^{4}$ This means, that it rests on a definition of the self that is shared by the person, other people and society at large. ${ }^{5}$ This is why identity is defined as "the traits and characteristics, social relations, roles, and social group memberships that define who one is". The concept of identity rests on two notions:

\section{i. Sameness (continuity) and \\ ii. Difference. ${ }^{6}$}

In the notion of continuity by describing our identity, we can be focused on the past (what used to be true of one), the present (what is true of one now), or the future (the person one expects or wishes to become, the person one feels obligated to try to become, or the person one fears one may become)., ${ }^{2,6-8}$ But in the notion of difference each individual is an essential human being with some characteristics, which are characteristic to him. Together, identities make up one's self-concept variously described as what comes to mind when one thinks of oneself. ${ }^{9,10}$
Feeling the continuity of the self during different areas of the life circle is crucial in the process of maintaining the self-concept. ${ }^{11}$ Feedback from the social environment and from important others which support the continuity of someone's identity also helps to maintain some ones self-concept. ${ }^{11-13}$ During our life time we are exposed to different stressful situations that may importantly affect our self-experience. Holmes \& Raha ${ }^{14}$ pointed out serious illnesses and injuries as the major stressors of our lives. Outcomes of schizophrenia and spinal cord injuries, which were the focus of our survey, also fit into this category. We are interested in these groups of people, because they have primary reduced functional abilities in two different areas - people after spinal cord injury have their limitations on their physical component and those with schizophrenia in their psychical functioning. The theoretical background of schizophrenia points out the importance of limited mental capacities, as the outcome of damages of executive functions (e. g.: planning, attention, inhibition, problem solving, working memory. ${ }^{15-18}$ On the contrary in people after spinal cord injury mental capacities are primary stable, while organic changes of the spinal cord are present. These changes result in lower physical functionality with damages of kinesiology and sensory experiencing; difficulties with bowel, respiration and imbalanced blood pressure are also present. ${ }^{19-21}$

These new conditions impact the life style of individuals, which is importantly connected with their identity. Studies, focusing in the self-concept of schizophrenia are more frequent than studies of the self-concept of people after spinal cord injury. Results of different researches ${ }^{3,17,22}$ show statistically important differences in selfexperiencing of people with schizophrenia compared to the general population. Importantly lower ratings on all areas of the self-concept (physical, moral, personal, family, social, academic) and the total self concept were found. ${ }^{23-25}$ It has long been recognized that schizophrenia is associated with a wide range of impairments in self-awareness and self-reflection abilities, with extreme consequences such as a disturbed sense of personal unity and continuity which are essential aspects of identity. ${ }^{26}$ A confused identity, following the impaired capabilities of the consistent self is present in people with schizophrenia. There is evidence that autobiographical memory is impaired in schizophrenia and it has been shown, in particular, that schizophrenia patients have difficulties in recalling specific autobiographical memories, that 
is, memories for unique episodes that occurred at a specific time and place and present a reduced conscious recollection of personal events. $^{27}$

The most studies of people after spinal cord injury highlight the importance of the physical self, which has the main impact on the total self concept and on the identity. The reconstruction of the self and identity post spinal cord injury is conceptualized as a pendulum, which suggests that identity reconstruction is a process that swings back and forth like a pendulum between the nondisabled and disabled aspects of self. It depicts five predominant identity views (outcomes):

a. The former self;

b. The supernormal identity;

c. The disabled identity as total self;

d. The disabled identity as an aspect of the total self; and

e. The middle self. These identity views are influenced by five experiences (processes).

These are:

a. Loss;

b. Sustainment;

c. Integration;

d. Continuity and

e. Development of the self. ${ }^{28}$

The psychological dimension or emotional adjustment, particularly self-perception and self-acceptance, however, is considered to be the most crucial indicator of achievement of rehabilitation goals; because unacceptance may lead to emotional disorders and pathologies like depression and anxiety. Carpenter ${ }^{29}$ summarizes, that staff perceive more psychological suffering than people with spinal cord injury describe. These inconsistencies of self-experiencing could be connected with the functioning of defense mechanisms. ${ }^{29,30}$

As we have described, the constancy of self-experiencing in people with schizophrenia and in those after spinal cord injury is disrupted. The main problem of our survey was to examine the connection between different aspects of self-concept and the identity. We hypothesized, that all aspects of the self-concept (physical, social, personal, moral, family, academic) in people with schizophrenia will be similarly connected with identity; while in the group of people after spinal cord injury, the physical self would have the main connection. In our hypotheses we also operationalized that because of the disrupted constancy of self-experiencing, there would be important differences between the real and the ideal self in both groups. People with schizophrenia have according to the theory a confused identity, they do not know, who they are; and in people after spinal cord injury the identity is conceptualized like a pendulum, where the Self is compared with the Self before the accident and with others. This is why we expect lower ratings of the Real Self and consecutively important differences between the Real and the Ideal Self.

\section{Material and methods}

\section{Participants}

Three groups of participants were enrolled into the study. Participants with DSM-IV diagnoses of schizophrenia $(\mathrm{n}=30)$ and those after spinal cord injury $(\mathrm{n}=30)$ were compared to the reference group of participants $(n=30)$ without mental or physical illnesses or injuries. The participants from the comparison groups were recruited with the help of nonprofit organizations. All participants with schizophrenia were in a post acute phase of illness as defined by having no hospitalizations or changes in medication or housing in the month prior to entering the study. Excluded from the study were participants with associated diseases. Participants after spinal cord injury were victims of an accident. Those with the injury following a degenerative illness were excluded. The sociodemographic characteristics of the resulting sample are detailed in Table 1.

Table I Sociodemographic characteristics of the participants in each group

\begin{tabular}{lllllllll}
\hline Optimistic & I & 2 & 3 & 4 & 5 & 6 & 7 & Pessimistic \\
Dependent & I & 2 & 3 & 4 & 5 & 6 & 7 & Independent \\
Clever & I & 2 & 3 & 4 & 5 & 6 & 7 & Clumsy \\
III & I & 2 & 3 & 4 & 5 & 6 & 7 & Healthy \\
Intelligent & I & 2 & 3 & 4 & 5 & 6 & 7 & unintelligent \\
Flexible & I & 2 & 3 & 4 & 5 & 6 & 7 & inflexible \\
Calm & I & 2 & 3 & 4 & 5 & 6 & 7 & lively \\
Sociable & I & 2 & 3 & 4 & 5 & 6 & 7 & antisocial \\
Interesting & I & 2 & 3 & 4 & 5 & 6 & 7 & boring \\
Physically attractive & I & 2 & 3 & 4 & 5 & 6 & 7 & Physically unattractive \\
Released & I & 2 & 3 & 4 & 5 & 6 & 7 & unreleased \\
Bad & I & 2 & 3 & 4 & 5 & 6 & 7 & good \\
Unappreciated & I & 2 & 3 & 4 & 5 & 6 & 7 & appreciated \\
Persistent & I & 2 & 3 & 4 & 5 & 6 & 7 & lenient \\
Unkind & I & 2 & 3 & 4 & 5 & 6 & 7 & kind \\
\hline
\end{tabular}

\section{Instruments}

Tennessee Self-Concept Scale (TSCS: 2; Fits and Warren ${ }^{3}$ ): The TSCS: 2 represents a widely used and multidimensional description of the self. ${ }^{3}$ We applied the revised and updated version of the adult questionnaire with 82 items. The basic scores are the two Summary Scores: Total Self Concept (TOT) and Conflict (CON) and the six Self-Concept Scales: Physical (PHY), Moral (MOR), Personal (PER), Family (FAM), Social (SOC) and Academic/Work (ACA). Validity scores for examining response bias - Inconsistent Responding (INC), Self-Criticism (SC), Faking Good (FG), and Response Distribution (RD) are provided. There are also three Supplementary Scores, which involve combining items from some of the basic scales in a way that reflects the original theoretical thrust of the test. These Scores are: Identity (IDN), Satisfaction (SAT) and Behavior (BHV). The validity scores are designed to identify defensive, guarded, socially desirable, or other unusual or distorted response patterns; and the Supplementary scores are groups of TSCS:2 items from each Self-Concept subscale that have historically been classified as expressing one of the primary messages:

I. This is who I am, this is how I identify myself, or Identity (IDN);

II. This is how satisfied I am with myself, or Satisfaction (SAT); and

III. This is what I do, this is how I behave, or Behavior (BHV).

These are the scores that have been delineated on a theoretical basis only, and they are assumed to represent an internal frame of reference within which the individual describes himself or herself ${ }^{3}$. The task of the participant is to read each statement carefully and decide how well it describes himself. Then he has to circle the number on the 5-point Liker Scale (1 - always false, 2 - mostly false, 3 partly false and partly true, $4-$ mostly true, 5 - always true), which is the most suitable for him. 
The self evaluation: This is a semantic differential, composited on the basic of the Me - Ideal Me schema. This task was composited by the author of the article. 15 personality characteristics, which describe the physical, social and personal self, were included. The characteristics were selected on the basis of the research, performed by Lamovec $\mathrm{T}^{31}$ and on the basis of the previous subjective experiences with persons with schizophrenia and with those after spinal-cord injury. The participants had to describe themselves by choosing a range between extremes of each characteristic. They had to evaluate their Real Self and their Ideal Self. We are adding the Scale with introductions, if there would be any interest in repeating the survey.

\section{Participants had this introduction}

We are interested in how you experience yourself. Please, evaluate each characteristic on a 7-point scale. 4 represents a neutral value, while 1 and 7 are the extreme values. Circle the value which suits the experience of yourself (about what you are) the most. Please, assess quickly. Now try to evaluate, what kind of a person would you like to be.

The positive extreme has the greatest value, so firstly we performed reverse scoring and then summarized the values. The analysis of the reliability (Table 2) for each group and for each scale shows, that the results of the test battery are the most reliable in the reference group. Cronbach $\alpha$ coefficients in the reference group and in the group of participants with schizophrenia are comparable. Green et al., ${ }^{32}$ describe them as coefficients with good reliability. On the contrary, results in the group of participants after spinal cord injury are lower on all scales and are therefore placed in the range of acceptable reliability.

Table 2 Cronbach's $\alpha$ coefficients for each scale of the TSCS and for the Semantic differential in all groups of participants

\begin{tabular}{|c|c|c|c|c|c|c|}
\hline & \multicolumn{2}{|c|}{$\begin{array}{l}\text { Participants } \\
\text { with } \\
\text { Schizophrenia }\end{array}$} & \multicolumn{2}{|c|}{$\begin{array}{l}\text { Participants } \\
\text { with Spinal } \\
\text { Cord Injury }\end{array}$} & \multicolumn{2}{|c|}{$\begin{array}{l}\text { Reference } \\
\text { Group }\end{array}$} \\
\hline & $\mathbf{N}$ & $\%$ & $\mathbf{N}$ & $\%$ & $\mathbf{N}$ & $\%$ \\
\hline \multicolumn{7}{|l|}{ Gender } \\
\hline Male & 15 & 15 & 17 & 56.7 & 15 & 50 \\
\hline Female & 50 & 50 & 13 & 43.3 & 15 & 50 \\
\hline \multicolumn{7}{|l|}{ Age } \\
\hline$M$ & 44.33 & & 42.07 & & 38.2 & \\
\hline SD & 11.8 & & 11.16 & & $1 \mathrm{I} .45$ & \\
\hline \multicolumn{7}{|c|}{ Time of Education } \\
\hline M & 12.63 & & 12.8 & & 12.5 & \\
\hline SD & 3.59 & & 1.69 & & 3.15 & \\
\hline \multicolumn{7}{|l|}{ Status } \\
\hline \multirow{3}{*}{$\begin{array}{l}\text { Married } \\
\text { In } \\
\text { Relationship } \\
\text { Widowed }\end{array}$} & 3 & 10 & II & 36.7 & 15 & 50 \\
\hline & 8 & 26.7 & 3 & 10 & 10 & 33.3 \\
\hline & 2 & 6.7 & 0 & 0 & I & 3.3 \\
\hline Single & 13 & 43.3 & 14 & 46.7 & 4 & 13.3 \\
\hline Divorced & 4 & 13.3 & 2 & 6.7 & 0 & 0 \\
\hline
\end{tabular}

*Note: $\mathrm{N}$ (in each group) $=30$

\section{Procedure}

The data was collected from August 2012 till the end of February 2013. The study was approved by the National Medical Ethics Committee of the Republic of Slovenia (NMEC). All investigations were in accordance to the protocol and followed the ethical and humane principles of research. Written informed consent for participation and publication has been obtained. All participants completed the test battery in the form of a pen-and-paper type of assessment.

\section{Data analysis}

The data were analyzed with the program SPSS 18. Before further analysis of the data we implemented the Kolmogorov-Smirnov z-test for all groups of participants and for all scales. Because violations of normality and/or homogeneity of variance were detected in some variables, a combination of parametric and nonparametric tests was applied in further analysis. Correlations between the scales in each group of participants were evaluated with Sperman Rank correlation. Comparison of self-experiencing on different aspects of the SelfConcept and between the Real and the Ideal Self was held with the Kruskal-Wallis test. Because the data on the Satisfaction scale and the Difference between the Real and the Ideal Self were normally distributed, a Linear Regression was obtained.

\section{Results}

We calculated Spearman's correlations between the scales of the TSCS: 2 for all group of participants. The results are presented in Table 3. We can see, that the Supplementary Scores (IDN, SAT and BHV) form the most statistically important and the highest correlations with other scales. Between the Validity Scores in all groups of participants Faking Good (FG) and Response Distribution (RD) are those with the most statistically important correlations with other scales. There could be seen some differences in the height of correlation coefficient between the groups of participants. We can expose the Family SelfConcept Scale, which forms in the group of participant after spinalcord injury statistically important correlations with most of the subscales; while in the other comparison and the reference group the correlations are not of such importance. We perceive as interesting the correlation between the Academic/Work Self-Concept scale and the Physical Self-Concept Scale, which is not important in the group of people after spinal cord injury, while in the other groups the correlation has the importance on statistical level of 0.01 . Because the data on some scales did not distribute normally, we were not allowed to perform the regression analysis.

To see the differences in self-experiencing between the groups, the Kruskal Wallis test was performed. Statistically important differences are seen in evaluations of: Faking Good, Identity, Behavior, Physical Self-Concept, Family Self-Concept, Social Self-Concept and the Total Self-Concept, where in all cases the participants with schizophrenia gave the lowest rankings. The differences in evaluating the Identity, the Total Self-Concept and the Family Self-Concept are statistically most important (Table 4).

The participants were also asked to evaluate their Real and Ideal Self. Once more we examined the differences with the Kruskal-Wallis test. The results show that the groups of participants statistically importantly distinguish in their evaluations of the Real self $\left(\chi^{2}=\right.$ 10.827, $p=.004$; Mean Rank schizophrenia $=32.84$, Mean Rank spinalcord $=$ 50.20 , Mean Rank referencegroup $=53.47)$ and in the Difference $\left(\chi^{2}=\right.$ $8.240, p=.016$; Mean Rank schizonhrenin $^{\text {referegroup }}=35.00$, Mean Rank $_{\text {spinalcord }}=$ 54.05 , Mean Rank $\left._{\text {reference group }}=47.45\right)$, which represents the deviation between the Ideal and the Real Self (Difference = Ideal Self - Real Self). Participants in the group after spinal cord injury showed the major tendency for changing their Self. The Mean Rank of Difference is in this group the highest.

With Linear Regression Analysis we examined if Satisfaction of participants with their self-concept could be predicted on the basis 
of the Difference between the Ideal and the Real Self. In the group of people with schizophrenia the predictor could explain $3.8 \%$ of variance (Adjusted $\mathrm{R}^{2}=.038$ ), in the group of participants after spinal cord injury $0 \%$ (Adjusted $\mathrm{R}^{2}=.000$ ) and in the reference group $2.9 \%$ (Adjusted $\mathrm{R}^{2}=.029$ ). Difference was not a statistically important predictor.

Table 3 Sperman's $\rho$ coefficients

\begin{tabular}{lllll}
\hline & $\begin{array}{l}\text { People with } \\
\text { Schizophrenia }\end{array}$ & $\begin{array}{l}\text { People After Spinal } \\
\text { Cord Injury }\end{array}$ & $\begin{array}{l}\text { Reference } \\
\text { Group }\end{array}$ & $\begin{array}{l}\text { All } \\
\text { Together }\end{array}$ \\
\hline Inconsistent Responding & 0.861 & 0.762 & 0.893 & 0.847 \\
Faking Good & 0.855 & 0.748 & 0.886 & 0.837 \\
Self-Criticism & 0.863 & 0.758 & 0.902 & 0.849 \\
Response Distribution & 0.84 & 0.717 & 0.87 & 0.821 \\
Identity & 0.836 & 0.716 & 0.875 & 0.817 \\
Satisfaction & 0.84 & 0.715 & 0.876 & 0.821 \\
Behavior & 0.837 & 0.719 & 0.874 & 0.819 \\
Physical Self-Concept & 0.844 & 0.732 & 0.879 & 0.827 \\
Moral Self-Concept & 0.848 & 0.733 & 0.882 & 0.831 \\
Personal Self-Concept & 0.842 & 0.736 & 0.879 & 0.828 \\
Family Self-Concept & 0.858 & 0.732 & 0.888 & 0.833 \\
Social Self-Concept & 0.844 & 0.735 & 0.882 & 0.829 \\
Academic Self-Concept & 0.849 & 0.75 & 0.883 & 0.835 \\
Total Self-Concept & 0.838 & 0.7 & 0.892 & 0.823 \\
Conflict & 0.885 & 0.883 & 0.907 & 0.894 \\
Real Self & 0.845 & 0.735 & 0.878 & 0.825 \\
Ideal Self & 0.858 & 0.753 & 0.885 & 0.839 \\
Together & 0.858 & 0.758 & 0.89 & 0.843 \\
\hline
\end{tabular}

*Note: $-p<.05 ; * *-p<.01 ; \mathrm{N}$ (in each group) $=30$

Table 4 Results of the Kruskal-Walis test for scales on the TSCS

\begin{tabular}{|c|c|c|c|c|c|}
\hline & \multicolumn{5}{|l|}{ Mean Rank } \\
\hline & $\begin{array}{l}\text { People with } \\
\text { Schizophrenia }\end{array}$ & $\begin{array}{l}\text { People After Spinal Cord } \\
\text { Injury }\end{array}$ & $\begin{array}{l}\text { Reference } \\
\text { Group }\end{array}$ & $\mathbf{X} 2$ & $\mathbf{p}$ \\
\hline Inconsistent Responding & 48.92 & 48.45 & 39.13 & 2.722 & 0.256 \\
\hline Faking Good & 35.08 & 46.73 & 54.68 & 8.59 & $.014^{*}$ \\
\hline Self-Criticism & 41.97 & 53.73 & 40.8 & 4.524 & 0.104 \\
\hline Response Distribution & 42.35 & 49.67 & 44.48 & 1.246 & 0.536 \\
\hline Identity & 29.48 & 50 & 57.02 & 1.021 & $.000 * *$ \\
\hline Satisfaction & 36.8 & 48.75 & 50.95 & 5.105 & 0.078 \\
\hline Behavior & 34.57 & 48.37 & 53.57 & 8.494 & $.014^{*}$ \\
\hline Physical Self-Concept & 36.82 & 46.23 & 53.45 & 6.13 & $.047^{*}$ \\
\hline Moral Self-Concept & 39.38 & 46.45 & 50.67 & 2.87 & 0.238 \\
\hline Personal Self-Concept & 40.32 & 45.28 & 50.9 & 2.475 & 0.29 \\
\hline Family Self-Concept & 26.1 & 51.58 & 58.72 & 2.957 & $.000 * *$ \\
\hline Social Self-Concept & 35.63 & 51.45 & 49.42 & 6.533 & $.038^{*}$ \\
\hline Academic/Work Self-Concept & 42.37 & 39.87 & 54.27 & 5.218 & 0.074 \\
\hline Total Self-Concept & 33.8 & 47.52 & 55.18 & 1.322 & $.006 * *$ \\
\hline Conflict & 50.5 & 42.03 & 43.97 & 1.733 & 0.421 \\
\hline
\end{tabular}

*Note: - $\mathrm{p}<.05$; ** - $\mathrm{p}<.0$ I; IR - Inconsistent Responding; FG - Faking Good; SC - Self-Criticism; RD - Response

Distribution; IDN - Identity; SAT - Satisfaction; BHV - Behavior; PHY - Physical Self-Concept; MOR - Moral Self-Concept; PER - Personal Self-Concept; FAM Family Self-Concept; SOC - Social Self-Concept;ACA - Academic/Work Self-Concept; TOT - Total Self-Concept; CON - Conflict; N (in each group) = 30

\section{Discussion}

Prior literature has conceptualized the importance of the sameness (continuity) by describing our identity. ${ }^{6-8}$ Serious illnesses and injuries are pointed out as stressors with a great impact on the process of selfexperiencing. ${ }^{14}$ The aim of our study was to examine, how different aspects of self concept are connected with identity in people with schizophrenia and in those after spinal cord injury. A disruption of the constancy of self-experiencing is present in both groups.
We hypothesized, that all aspects of self concept (physical, social, personal, moral, family, academic) in people with schizophrenia will be similarly connected with identity; while in the group of people after spinal cord injury, the physical self would have the main connection. Regarding the correlations presented in Table 3 we cannot expose noticeable differences between the groups focused on the evaluation of Identity. The Scale is statistically importantly correlated with all Self-Concept Scales, especially with the ratings of the Total Self-Concept. Further analysis with the nonparametric 
Kruskal-Wallis test was performed. The results (Table 4) show statistically important differences in evaluation of Identity between the three groups. The mean ranks are the lowest in the group of participants with schizophrenia, which indicates problems in defining the Self in people with this diagnosis. According to the literature (Sass \& + Parnass, 2003) answering questions about themselves (eg.: Who am I? Where do I belong?) force a great effort. Further one in the group of participants with schizophrenia compared to other two groups lower ratings of all areas of self-concept (Physical, Moral, Personal, Family, Social, Academic) ant the Total Self-Concept are found (Table 4), where the evaluations of the Physical, Family, Social and Total Self-Concept differ in a statistically important manner. People with schizophrenia show dissatisfaction or lower rates of satisfaction with their body, physical appearance and state of health. Compared to people after spinal cord injury and the reference group they experience themselves as people with lower abilities and skills. Focusing on the individual's perception of Self in relation to his or her immediate circle of associates people with schizophrenia indicate a sense of alienation from or disappointment in their families and a lack of social skills. Results of our study support conclusions of previous studies ${ }^{3,17,22}$ where statistically important differences in selfexperiencing of people with schizophrenia compared to the general population were found. Low ratings indicate after Fits \& Warren dissatisfaction or even uncertainty about themselves. This fits into the description of confused identity. ${ }^{27}$

On the contrary we expected important correlations between Identity and the Physical Self, which we suspected to be the highest in the group of people with the experience of spinal cord injury. The correlation in Table 3 is statistically important and the highest and positive, but it is similar to the correlations in other groups. The Kruskal-Wallis test (Table 4) shows that the ratings of the Physical SelfConcept are between the groups statistically important. Evaluations of participants with spinal cord injury are between the ratings of people with schizophrenia (the lowest ratings) and the reference group (the highest ratings). On this point we should think about the validity and reliability of answering. Cronbach's $\alpha$ coeffecients (Table 2) in the group of participants with spinal cord injury are lower and placed in the range of acceptable reliability, while the coefficients in the group with people with schizophrenia and in the reference group introduce a good reliability. ${ }^{32}$ In this group are also the validity scales (Table 3) rated very high, although the differences are not statistically important. Maybe here could be seen a tendency of functioning under defense mechanisms. ${ }^{30}$ According to Carpenter ${ }^{29}$ people with spinal cord injury experience themselves in a better psychical condition, than the staff perceives and describes them.

The functioning of defense mechanism could be also connected with the evaluations of the Real and the Ideal Self. In our hypotheses we also operationalized that because of the disrupted constancy of self-experiencing, there would be important differences between the Real and the Ideal self in both groups. The Difference between the groups of participants is statistically important and is the highest in the group of people after spinal cord injury. These people try to be different as they are, which is connected with the conceptualization of the identity as a pendulum, which suggests that identity reconstruction is a process that swings back and forth like a pendulum between the nondisabled and disabled aspects of self. This process includes social comparisons (comparisons with others) and comparisons of the actual Self with the prior, before the accident.

We have to highlight some limitations of our survey. If there would be a repetition of the study, a larger sample of participants should be included. Interesting and of high importance could be the results of a longitudinal study, where we could apply self-concept evaluations of the same persons but in different life periods. An insight into the process of self-experiencing in people with pathology could be enabled. According to the results of our study, we can conclude, that as we expected, the identity of people with schizophrenia and those after spinal cord injury is specific. People with schizophrenia experience themselves negatively and are confused about their identity, while those with spinal cord injury are oriented to become different and idealize and stand out in ratings of their Ideal Self. Studies in which self evaluations of people with schizophrenia were compared to the evaluations of them given by their relatives have already been done. ${ }^{23}$ Because of diminished self-experiencing ${ }^{29}$ in people after spinal cord injury is present, maybe it would be of great value to make similar with these group of people.

\section{Summary}

To summarize, we see a great impact of our study in the connection of psychological work with both populations. In the process of psychosocial rehabilitation of people with schizophrenia the meaning of different areas of the Self-Concept should be emphasized. The patients should also be educated about the impact of negative SelfConcepts on their functioning in their everyday life. Nowadays the emphasis in the process of rehabilitation in people with schizophrenia is on inclusion in the social environment, while the sense of the SelfConcept is somehow neglected. People after spinal cord injury have great expectations about their ideal identity, which may escalate the functioning of defense mechanisms. The individual rehabilitation should be enriched through psychotherapy and collaborations with relatives. Such enlarged treatment with the emphasis on the selfexperience and identity could enable a wider aspect on the new Self.

\section{Acrknowledgmwents}

None.

\section{Conflicts of interest}

Author declares there are no conflicts of interest.

\section{Funding}

None.

\section{References}

1. Fivush R. The development of autobiographical memory. Annu Rev Psychol. 2011;62:559-582.

2. Baumeister RF. Self-Concept, Self-Esteem and Identity. In Derlega VJ, et al. (Eds.), Personality: Contemporary Theory and Research ( $3^{\text {rd }}$ edn) Nelson-Hall, Chicago, USA. 2005. p. 246-280.

3. Fitts WH, Warren WL. Tennessee Self-Concept Scale (TSCS: 2), Second edition manual. Western psychological services, Los Angeles, USA. 1996.

4. Oyserman D, Elmore K, Smith G. Self, Self-Concept, and Identity. In: Leary MR \& Tangrey JP (Eds.), Handbook of Self and Identity ( $2^{\text {nd }}$ edn $)$, The Guilford Press, New York, USA. 2012. p. 69-101.

5. Gecas V. The Self-Concept. Annual Review of Sociology. 1982;8:1-33.

6. Oyserman D. Social identity and self regulation. In: Kruglanski AW \& Higgins ET (Eds.), Social psychology: Handbook of basic principles (2 $2^{\text {nd }}$ edn), Guilford Press, New York, USA. 2007. p. 432-453.

7. Oyserman D. Identity-based motivation: Implications for actionreadiness, proceduralreadiness, and consumer behavior. Journal of Consumer Psychology. 2009;19:250-260. 
8. Oyserman D. Identity-based motivation and consumer behavior: Response to commentary. Journal of Consumer Psychology. 2009; 19:276-279.

9. Stets JE, Burke PJ. A Sociological Approach to Self and Identity. In: Leary MR, Tangney JP (Eds.), Handbook of Self and Identity. The Guilford Press, New York, USA. 2003. p.128-152.

10. Stryker $\mathrm{S}$. The interplay of affect and identity: Exploring the relationships of social structure, social interaction, self, and emotion. American Sociological Association, Chicago, USA. 1987.

11. Brewer MB, Gardner W (1996) Who Is This "We"? Levels of Collective Identity and Self Representations. Journal of Personality and Social Psychology 71 (1): 83-93.

12. Benedik E. Doživljanje samega sebe in pomembnih drugih oseb psihiatričnih bolnikov. [Experience of oneself and other persons relevant psychiatric patients (Doktorska disertacija). Filozofska fakulteta, Ljubljana. 2000.

13. Benedik E. Kako psihiatrični bolniki doživljajo samega sebe in bližnje osebe. [How psychiatric patients experience the self and significant. Anthropos . 2000;51-62.

14. Amiram BV, Selzer ML. Desirable versus undesirable life events: Their relationship to stress and mental distress. J Pers Soc Psychol . 1975;32(2):329-337.

15. Goldberg TE, David A, Gold JM. Neurocognitive impairments in schizophrenia: their character and roole in symptom formation. In Weinberg DR, Harrison PJ (Eds.), Schizophrenia ( $3^{\text {rd }}$ edn), WileyBlachwell, UK. 2011. p.142-162.

16. Groznik M. Oviranosti in potrebe po rehabilitaciji ambulantnih bolnikov s shizofrenijo. Med razgl. 1999;38:485-486.

17. Yanos PT, Roe D, Lysaker PH. The Impact of Illness Identity on Recovery from Severe Mental Illness. Am J Psychiatr Rehabil. 2010;13(2):73-93.

18. Walker E, Tessner K.Schizophrenia. Association of Psychological Science. 2008;3(1):30-37.

19. Anderson KD. Targeting Recovery: Priorities of the Spinal Cord-Injured Population. J Neurotrauma . 2004;21(10):1371-1383.

20. Frank RG, Rosenthal M, Caplan B. Handbook of rehabilitation Psychology. (2 ${ }^{\text {nd }}$ edn), American Psychological Association, Washington, USA. 2009
21. Pollard C, Kennedy P. A longitudinal analysis of emotional impact, coping strategies and post-traumatic psychological growth following spinal cord injury: A 10-year review. Br J Health Psychol. 2007;12(Pt 3):347-362

22. Conway MA. Memory ant the self. Journal of Memory and Language. 2005;53:594-628.

23. Lehman AF. Measuring Quality of Life in a Reformed Health System. Health Aff (Millwood). 1995;14(3):90-101.

24. Lehman AF. Quality Of Care In Mental Health: The Case Of Schizophrenia. Health affairs. 1999;18(5):52-65.

25. Lehman AF, Fischer EP, Postrado L, et al. The Schizophrenia Care and Assessment Program Health Questionnaire (SCAP-HQ): An Instrument to Assess Outcomes of Schizophrenia Care. Schizophr Bull. $2003 ; 29(2): 247-256$.

26. Maj M. The self and schizophrenia: some open issues. World Psychiatry. 2005;11(2):65-66.

27. Dimaggio G, Salvatore G, Popolo R, et al. Autobiographical memory and mentalizing impairment in personality disorders and schizophrenia: clinical and research implications. Front Psychol. 2012;3:529.

28. Yoshida KK. Reshaping of self: a pendular reconstruction of self and identity among adults with traumatic spinal cord injury. Sociology of Health \& Illness. 1993;15(2):217-245.

29. Carpenter C. The Experience of Spinal Cord Injury: The Individual's Perspective-Implications for Rehabilitation Practice. Phys Ther. 1994;74(7):614-628.

30. Westie KS. Psychological Aspects of Spinal Cord Injury. Clinical Prosthetic and Orthotics. 1987;11(4):225-229.

31. Lamovec T. Psihodiagnostika osebnosti 1, 2. Ljubljana: Znanstveni inštitut Filozofske fakultete. 1994.

32. Green SB, Lissitz RW, Mulaik S. Limitations of coefficient alpha as an index of test unidimensionality. Journal of Educational and Psychological Measurement. 1977;37:827-839. 